1. Doutora e Mestre pela FAU-USP, professora e pesquisadora do POSURB PUC-Campinas, Pós-doutorado no King's College London. Participa do Grupo de Pesquisa História da Cidade: Ocupação Territorial e Ideários Urbanos, linha de pesquisa História do Pensamento Urbanístico. Janevictal@ puc-campias.edu.br

2. Doutorando pelo POSURB da PUC-Campinas, bolsista Capes, Mestre pelo POSURB PUC-Campinas e Graduado em Arquitetura e Urbanismo, professor pela FIAM FAAM e Unicid SP. Participa do Grupo de Pesquisa História da Cidades: Ocupação Territorial e Ideários Urbanos, linha de pesquisa História do Pensamento Urbanístico. rodrigovias@hotmail.com

\title{
DOI: 10.5752/P.2316-1752.2015v22n31p142
}




\title{
FLUXO, MIGRAÇÃO E FIXAÇÃO NA CAPITANIA DE SÃO VICENTE: O VETOR DE EXPANSÃO URBANA NO VALE DO PARAÍBA
}

\author{
FLOW, MIGRATION AND SETTLEMENT INTHE CAPTAINCY OF SÃO \\ VICENTE: THE URBAN EXPANSION VECTOR INTHE PARAÍBA VALLEY
}

FLUJO, MIGRACIÓNY ASENTAMIENTO EN LA CAPITANÍA DE

SAN VICENTE : EL VECTOR DE LA EXPANSIÓN URBANA EN EL

VALLE DEL PARAÍBA

\author{
Jane Victal ${ }^{1}$ \\ Rodrigo Vitorino Assumpção ${ }^{2}$
}

\section{Resumo}

Este trabalho apresenta um dos vetores de expansão territorial, no Período Colonial, a partir do litoral em direção ao sertão da Capitania de São Vicente, com ênfase para a ocupação do Vale do Paraíba paulista, em três momentos: a ocupação jesuítica do planalto, a expansão territorial em direção ao Vale do Paraíba e a transposição da Serra da Mantiqueira em direção às minas de ouro. Apresenta ainda como esse caminho se consolidou por meio da cultura cafeeira na região do Vale.

Palavras-chave: Vale do Paraíba. Expansão territorial. Caminhos. Colonização. Povoamento.

\begin{abstract}
This article presents one of the territorial expansion vectors in the colonial period from the coast towards the wilderness of São Vicente Capitaincy, emphasizing the occupancy of Vale do Paraíba in the state of São Paulo at three stages: the Jesuit plateau occupancy, the territorial expansion towards the Vale do Paraíba and the Serra da Mantiqueira transposition in the direction of the gold mines. Furthermore it also presents how this path has been consolidated by means of the coffee production culture on the region of this valley.
\end{abstract}

Keywords: Vale do Paraíba. Territorial expansion. Pathway. Colonization. Settlement.

\begin{abstract}
Resumen
Este artículo presenta uno de los vectores de expansión territorial en el Período Colonial desde la costa hasta el interior de la Capitanía de São Vicente, con énfasis en la ocupación del Vale do Paraíba, en tres etapas: la ocupación de los jesuitas de la meseta, la expansión territorial en dirección a Vale do Paraíba y la transposición de la Serra da Mantiqueira en dirección de las minas de oro. También presenta cómo este camino se ha consolidado a través de la cultura del café en la región del Valle.
\end{abstract}

Palabras clave: Vale do Paraíba. Extensión territorial. Caminos. La colonización. Asentamiento. 


\section{Introdução}

A primeira forma de mobilidade presente no território da Capitania de São Vicente foi pautada pelos caminhos dos desbravadores, norteados pelo seu sistema hidrográfico e o conhecimento indígena da região. Os caminhos e trilhas do século $\mathrm{XVI}$ se formaram segundo o favorecimento da geografia, da hidrografia, principalmente dos rios e dos vales que proporcionaram as entradas mais profundas da colonização em direção ao sertão. Esses rios, embora não plenamente navegáveis em toda a extensão de seus cursos, além de serem os principais meios de comunicação, fornecendo um sistema de referência para os deslocamentos através território, propiciavam alimento e água para os povoamentos, além de possibilitarem posteriormente a criação do gado. Assim, como forneciam as condições básicas para a manutenção da vida no território isolado do planalto, no Período Colonial, foram surgindo os primeiros núcleos de aldeamento ao longo dos rios. Mobilidade e condições favoráveis à permanência possibilitaram o surgimento de aldeamentos numa sequência de pontos, seguindo o Vale do Paraíba. No entanto essa foi apenas uma condição básica, outras devem ser analisadas.

Para os conquistadores europeus, vindos do mar em direção ao continente, o desbravamento do território na altura do Vale do Rio Paraíba apresentava circunstâncias específicas. Numa extensão abrangendo da Bahia ao Sul do Brasil, encontra-se a Serra do Mar, que divide o território em duas áreas distintas: a costa litorânea e o planalto interior. A primeira consiste em uma faixa às vezes bastante estreita, de terrenos baixos, insalubres e de solo pouco fértil, onde primeiramente a colonização se estabeleceu. Essa conformação desfavorável à permanência e formação de núcleos urbanos ocorreu principalmente a partir do Sul do Rio de Janeiro, descendo em direção a São Paulo, precisamente na costa onde, tendo subido a Serra do Mar, encontra-se o Vale do Paraíba. Nesse ponto, a faixa litorânea se estreita ainda mais, e a serra segue seu curso em direção ao sul, formando uma barreira quase intransponível, onde, em alguns pontos, quando a topografia favorece, surgiram os mais antigos caminhos de entrada em direção ao planalto.

Um deles se deu por meio da consolidação da Trilha dos Tupiniquins (séc. XVI), também denominada de Caminho de Paranapiacaba ou Caminho de Piaçaguera, que foi a mais antiga e principal ligação entre o litoral e a vila de São Paulo de Piratininga, durante o Período Colonial. Iniciava-se na vila de São Vicente, atravessava uma área alagada e prosseguia ascendendo pela Serra do Mar até as nascentes do rio Tamanduateí, e daí ao córrego Anhangabaú, onde, segundo historiadores, encontrava-se a aldeia do índio Tibiriçá, em Piratininga. De Piratininga, podia-se subir pelo rio Tietê, que banhava as proximidades do sítio eleito para a fundação do colégio, que também podia ser acessado pelo Tamanduateí. O curso superior do rio Tietê, por sua vez, quase se confunde com o curso do rio Paraíba do Sul que, correndo em direção oposta àquele, constitui o prolongamento hidroviário natural em direção ao Vale do Paraíba, chegando até a foz deste rio, situada quase na fronteira dos atuais Estados do Rio de Janeiro e do Espírito Santo. 
Auguste de Saint-Hilaire (1822/1974), descreveu a região do Vale do Paraíba após deixar a Capitania de Minas Gerais e adentrar a Capitania de São Paulo. "Nos morros descortinávamos todo o território que se estende entre a cadeia marítima e a Serra da Mantiqueira, região que forma uma espécie de bacia entre as duas cadeias" (SAINT-HILAIRE, 1822/1974, p. 69).

\section{A população indígena e os primeiros jesuítas na Capitania de São Vicente}

A ocupação do planalto paulista se iniciou muito cedo, ao contrário de outras regiões do País. Isso se deveu principalmente a quatro fatores: 1) a condição desfavorável à permanência na costa litorânea; 2) a presença indígena no planalto, oferecendo mão de obra; 3) o trabalho de contato com os índios realizado por João Ramalho e o seu assentamento na aldeia que deu origem à Vila de Santo André da Borda do Campo; e 4) o projeto jesuítico confiado ao padre Manoel da Nóbrega que, mesmo tendo sido proibido de adentrar o sertão, fomentou a intensão de fundar uma casa jesuítica junto aos índios de Piratininga.

Assim, a presença do europeu no interior do sertão da Capitania de São Vicente ocorreu já no início do séc. XVI, mesmo sem a anuência da Coroa. A primeira rota ligava São Vicente a Piratininga, mas outras trilhas formavam um sistema rio/caminho, com seus pontos geográficos de referência, muito utilizados pelos índios tanto no planalto quanto na costa. Conforme a análise do "Mapa de distribuição e localização das tribos indígenas", organizado pelo Museu Nacional e publicado no texto "Introdução à Arqueologia", de Angyone Costa (1959), na região do Vale do Paraíba, enquanto os tupis habitavam as terras baixas da costa litorânea, incluindo a foz do rio Paraíba do Sul, os jês ocupavam o vale em quase toda a sua extensão, sendo que uma pequena parte do território entre essas duas etnias era ocupada por índios de línguas isoladas. ${ }^{3}$ Esses antigos e legítimos habitantes da terra detinham não somente o conhecimento das melhores rotas, mas também das formas de sobrevivência e de relacionamento com outros povos indígenas. A forma de domínio do território baseava-se, entre outros fatores, no conhecimento e deslocamento periódico pelo território.

Os jês habitavam vários pontos do País e dominavam territórios bastante amplos até o final do século XVI. Segundo Costa (1959, p. 226), habitaram a Amazônia antes de ali se fixarem os nu-aruaques e os tupis-guaranis, e de lá realizaram migrações, estabelecendo-se em regiões diferentes, como os atuais Estados do Espírito Santo e Minas Gerais, entre outras regiões, onde formaram o grupo timbira e aimoré-botocudo. Grupos da matriz jê, orientando-se de leste a oeste, deslocaram-se e ocuparam toda a região central do Brasil, atravessando o vale do rio São Francisco e restringindo-se apenas com a barreira geográfica da Serra do Mar, onde, descendo em direção ao mar, encontrava-se o território dos diversos grupos da matriz tupi. Estes últimos ocuparam e migraram ao longo de uma faixa que percorre totalmente o litoral brasileiro, indo desde o Uruguai até o Pará, contornando o território dos jês e pressionando-os em direção ao sertão. Segundo o estudo de Costa
3. A classificação etnográfica dos índios da América do Sul é realizada segundo os troncos linguísticos. Estudos também foram realizados pelos antropólogos e arqueólogos com base nas características fisiológicas. 
(1959), os tupis também pressionaram e adentraram o planalto, na região onde flui o rio Tietê, numa área que corresponde hoje ao Estado de São Paulo.

Assim, há indícios de que os Campos de Piratininga fossem amplamente ocupados por grupos indígenas e que, para os portugueses, havia a necessidade de estabelecer relações de amizade visando à conquista do sertão da Capitania e o acesso às riquezas da terra. Nesse sentido, a pessoa de João Ramalho, num primeiro momento, tornava-se uma das peças importantes para a colonização, já que havia contraído relacionamento de parentesco com o índio Tibiriçá, estabelecendo-se no planalto.

No entanto, como a empreitada de Nóbrega demonstrava obter sucesso devido aos seus métodos de catequese, este logo adquiriu mais prestígio do que João Ramalho dentro do contexto do projeto colonizador. Domesticados e cristianizados, os índios passaram a representar, para os portugueses, a possibilidade de acesso às riquezas, contribuindo então como guias em direção aos sertões. Assim, havia rotas consolidadas e os caminhos estavam abertos, mas ainda sem o devido controle da Coroa portuguesa, sendo estes, na sua maioria, compostos pelas antigas trilhas e cursos d'água utilizados pelos índios, que ofereciam pouca segurança e podiam ser percorridos por quem deles fizesse uso.

A grande mobilidade dos povoadores e dos mamelucos, atendendo aos desafios de riquezas que a terra prometia, decorria da vocação nômade do colono e do índio, que prosseguia por meio dos movimentos de marcha chamados de bandeiras, entradas, apresamentos e monções.

Vinham, em primeiro lugar, os preadores de índios, ou os catequistas, os foragidos, os degredados, os buscadores de ouro. Na linha de avanço seguinte, os criadores de gado, os lavradores e os mineradores, numa ordem de penetração variável [...]. Depois os mascates, os comerciantes modestos, os soldados, os funcionários, os homens de ofício, as autoridades e os representantes da inteligência da fronteira, que vieram a se tornar os políticos, os advogados, os párocos, os juízes do povo, as elites das vilas sertanejas (OMEGNA, 1971, p. 60).

Segundo o autor Jaelson Bitran Trindade (1977, p. 9), o Vale do Paraíba, no final do século XVII, era a "região mais povoada da Capitania de São Paulo", com uma densa aglomeração nas margens dos rios. Entretanto, para a formação dos primeiros focos de vida mais permanente, após a chegada dos forasteiros, errantes, aventureiros ou missioneiros, havia a necessidade de que chegassem aqueles voltados ao cultivo da terra. Formados os pousos ao longo dos caminhos, com o tempo, surgiam os colonizadores de temperamento mais sedentário, ou aqueles que, já tendo desbravado em muito, decidiam-se pela lavoura. Essa atividade geradora de permanência e de apropriação do território ocorreu segundo ciclos sucessivos de expansão com períodos alternantes de migrações e assentamentos, vindos dos mais antigos para os novos centros de fixação. 


\section{O primeiro ciclo de migração e fixação: do litoral ao planalto}

A ocupação do Vale do Paraíba ocorreu pelo ímpeto dos colonizadores que buscavam novas terras para o cultivo. Entretanto, na Capitania de São Vicente, a primeira leva de migração com nova fixação iniciou logo após a ocupação do litoral paulista, quando houve o anseio de estender os domínios da Coroa portuguesa, ainda no primeiro século da colonização. Para isso, foi necessário transpor a Serra do Mar, e esse acontecimento ocorreu devido ao estreitamento da faixa de terra entre a costa e a serra, ${ }^{4}$ onde o cultivo era restrito além do solo de baixa qualidade (PRADO JUNIOR, 1989, p. 9). Assim, garantir a sobrevivência e promover o assentamento do colonizador requeria o encontro de terras cultiváveis, levando-os a subir a serra em direção ao planalto.

A subida ao planalto foi realizada pelos colonizadores portugueses com o auxílio dos indígenas e de João Ramalho. ${ }^{5} \mathrm{O}$ planalto oferecia algumas vantagens se comparado ao litoral. Além do clima temperado, com constantes temperaturas médias e mais próximas ao encontrado pelo colonizador em sua terra natal e da terra mais própria à agricultura, sob o ponto de vista econômico, a presença de tribos indígenas dispersas fornecia mão de obra farta para os trabalhos na lavoura e carregamento de mercadorias (PRADO JUNIOR, 1989, p. 10). Essa ocupação dispersa de aldeias indígenas representava uma rede de grupos ligados entre si por laços familiares (MONTEI$R O$, 2004). A ocupação territorial do Planalto de Piratininga, após a fundação do núcleo de povoamento de Santo André da Borda do Campo, ocorreu pelos limites das várzeas dos rios Tamanduateí e Anhangabaú. Nela, a presença dos colonos foi demarcada com a construção, em 1554, do Colégio dos Jesuítas para a catequização dos índios e, posteriormente, com mais três edificações: o Convento de São Bento, o Colégio do Carmo e o Convento de São Francisco.

Ao subirem a serra encoberta por densa floresta, [... ] encontraram no planalto uma extensa área de vegetação rasteira, onde colinas se erguiam formando as meias laranjas e onde existiam dispersos agrupamentos de matas. Nesse planalto, foram fundados, inicialmente pelos jesuítas, um colégio para ensino e catequese dos índios, depois, pelo próprio governador, a cidade de São Paulo de Piratininga (TELLES, 2006, p. 28).

Sergio Buarque de Holanda (2006) aponta que a subida ao planalto e a fundação da Vila de Piratininga foi um "momento novo de nossa história nacional." Após a ocupação do Planalto de Piratininga, mesmo mantendo uma relação mercantil, houve o distanciamento maior entre a Coroa portuguesa e a Colônia. Mas esse foi também o momento do encontro e miscigenação de duas matrizes distintas: a europeia e a indígena, dando origem ao mameluco. Essa miscigenação étnica e cultural proporcionou aos paulistas características peculiares e importantes para a conquista de novas terras. De uma maneira geral, a miscigenação desse povo novo teve perdas e ganhos, a qual lhe condicionou um modo de vida muito peculiar. Era uma sociedade com
4. Telles (2006) verificou que esse acontecimento ocorreu também na cidade de Angra dos Reis-RJ, ainda no século XVI.

5. Os historiadores não são unânimes quanto à origem desse personagem da nossa história. John M. Monteiro (2004, p. 29) cita que não se sabe bem ao certo como teria chegado ao Brasil, sendo possível que tenha sido um náufrago de expedições portuguesas ou castelhanas no período entre 1510 a 1515. No Brasil, ele se casou com Bartira, filha do cacique Tibiriçá, e costumava organizar as comitivas que subiam do litoral ao planalto.

Cadernos de Arquitetura e Urbanismo, v.22, n.31, 2º sem. 2015 
poucas mulheres brancas e com uma grande mestiçagem entre homens brancos e índias. Um povo que perdeu a consciência da vida comunitária e da disciplina patriarcal que existia nas vilas agrárias tradicionais da cultura portuguesa ao mesmo tempo em que perdeu a autonomia da vida igualitária, sem distinção de classes sociais proveniente da cultura indígena. Contudo houve uma unificação dos conhecimentos militares portugueses aos de sobrevivência e deslocamentos indígenas no território inóspito (RIBEIRO, 1995, p. 366).

O paulista era um povo pobre, que vivia da agricultura de subsistência. Uma vida simplória, mas com o anseio de crescimento econômico, "aspiravam a participar da camada dominante, dar-se luxos de consumo e poder influenciar e mandar" (RIBEIRO, 1995, p. 367). Esses fatores proporcionavam ao paulista certa liberdade para organizar algumas expedições rudimentares ao sertão. Até então, não existia uma preocupação em conquistar novas terras com o intuito comercial e econômico. Esse quadro somente mudou a partir do descobrimento das minas de ouro.

Portanto, em 1554, o centro da Capitania deslocou-se do litoral ao planalto. ${ }^{6}$ Isso proporcionou que a Vila de Piratininga fosse um eixo de ligação, um ponto nodal entre o litoral e o sertão. Caio Prado Junior (1989) nos apresenta esse fenômeno em um gráfico simplificado, no qual temos a cidade de Santos como entrada da Capitania e eixo de ligação entre o litoral e o planalto. Posteriormente, apresenta os cinco vetores de expansão que partiam da Vila de Piratininga ao sertão, além do caminho do mar (PRADO JUNIOR, 1989, p. 30). Para exemplificar meIhor o gráfico de Caio Prado Junior, buscamos uma cartografia que pudesse demonstrar esses caminhos. Podemos observar em um detalhe do "Mappa Corographico da Capitania de São Paulo", datado de 1837 (FIG. 1), cinco dos caminhos descritos por Caio Prado Junior: o caminho do mar, o caminho do Vale do Paraíba, o caminho do sul de Minas, o caminho dos Guaianases e o caminho do vale do rio Tiete. Vale dizer que o caminho dos Campos de Sorocaba é uma ramificação do caminho do vale do rio Tiete.

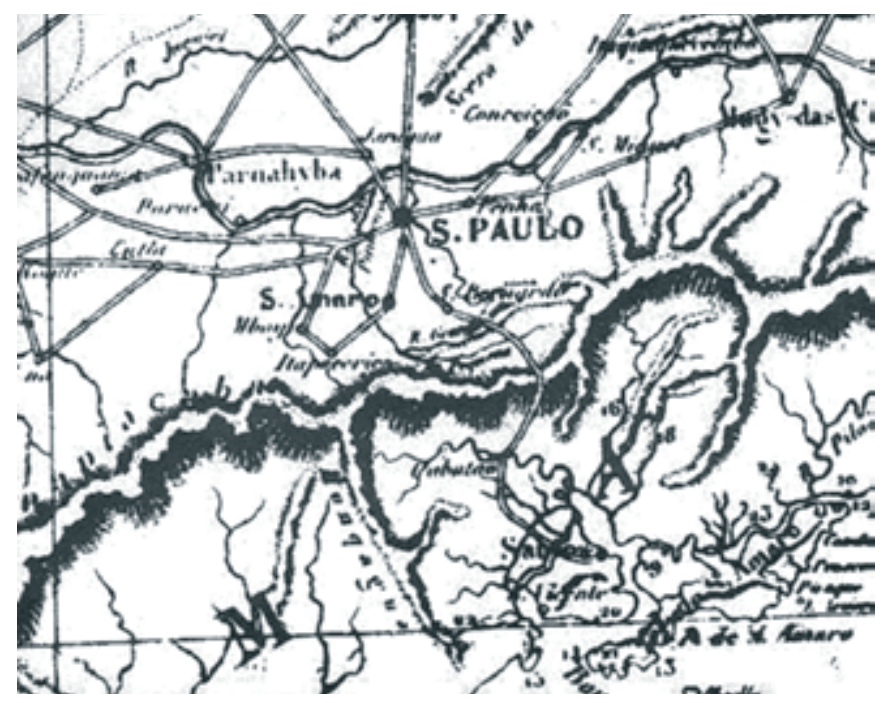

6. Com essas melhores condições para sobrevivência houve uma migração de colonos do litoral ao planalto. Prado Junior (1989) salienta que chegou a haver a preocupação quanto ao "despovoamento completo do litoral." Sérgio Buarque de Holanda (2006) também cita que a Coroa portuguesa criava dificuldades para a ocupação de terra adentro, justamente com medo do despovoamento da marinha.

Figura 1 - Detalhe do Mappa Corographico da Capitania de São Paulo, 1837

Fonte: Collectanea de Mappas da Cartographia Antiga da Capitania de São Paulo, 1922 


\section{O segundo ciclo de migração e fixação: o caminho dos bandeirantes e o início da apropriação territorial no Vale do Paraíba, no século $X V I I$}

Era de São Paulo que os bandeirantes estabeleciam seus percursos ao sertão. ${ }^{7}$ Os próprios bandeirantes eram descendentes de indígenas e inicialmente adentraram aos sertões com a função de capturar índios para servirem de mão de obra escrava nas lavouras de cana-de-açúcar do Nordeste e do litoral paulista. Os indígenas tinham também um importante papel para subsidiar as ações portuguesas. Os colonos escravizavam os índios para trabalhar nas construções, agricultura, transporte e até servirem de tradutores nas tribos. Os padres jesuítas também conduziam a aculturação cristã aos indígenas como forma de dominação.

Sucedeu que vindo os paulistas naquele tempo fazerem entrada ao gentio e estas partes para o conduzirem para São Paulo por negócio, e se servirem dele conduzindo os de menor idade porque melhor se thes adomava e por doméstico (TAUNAY, 1981, p. 65).

Além da apropriação dos conhecimentos indígenas pelos colonos, a Vila de Piratininga foi fundada justamente no centro de um sistema hidrográfico que, quando não navegável, oferecia as referências para os deslocamentos no território. Portanto a Vila estava localizada em um ponto estratégico da Capitania. Esse fato possibilitou a utilização dos rios como vetores de expansão territorial, abrindo caminhos aos sertões (PRADO JUNIOR, 1989, p. 20). Um desses caminhos, mais tarde conhecido como "Caminho dos Bandeirantes", seguia em direção ao Vale do Paraíba, partindo do leste de São Paulo. Entretanto, com a descoberta das minas de ouro no século XVII, houve a intensificação do tráfego de pessoas por essa via.

O ouro foi primeiramente encontrado nos sertões de Taubaté, nas margens dos rios, também conhecido como ouro de aluvião (RIBEIRO, 1995, p. 372). Os bandeirantes ocuparam as margens dos rios e expandiram os caminhos no sentido das minas, acreditando que o ouro pudesse ser encontrado ao longo de toda extensão fluvial, e assim seguiram seu leito em busca do metal. É possível, portanto, que a ocupação do território mineiro tenha sido realizada basicamente pelos povoadores paulistas. Havia uma política da Coroa portuguesa em ocupar o território do Vale do Paraíba, juntamente com os interesses de estabelecer ligações do planalto com o litoral norte da capitania (MÜLLER, 1969, p. 13). Assim, no fim do século XVI e início do século XVII, as primeiras sesmarias na região do Vale do Paraíba foram doadas, e alguns núcleos urbanos, vilas e freguesias foram fundadas. ${ }^{8}$ Esses foram pontos importantes na organização territorial da colônia. O que encontramos também no Vale do Paraíba são as "Aldeia dos Reis", principalmente entre o litoral e o rio Paraíba do Sul. Esses aldeamentos eram unidades fixas de indígenas "amigos", sob supervisão e administração dos jesuítas. A Aldeia dos Reis tinham duas finalidades: a primeira dizia respeito a criar e manter as relações territoriais com o planalto; enquanto a segunda referia-se à proteção territorial (MONTEIRO, 2004, p. 31).
7. Sergio Buarque (2006, p. 102) esclarece o que não são mais os colonizadores portugueses os organizadores das Bandeiras. Em um trecho ele diz: "A expansão dos pioneers paulistas não tinha suas raízes do outro lado do oceano, podia dispensar o estímulo da metrópole e fazia-se frequentemente contra a vontade e contras os interesses imediatos desta".

8. No fim do século XVII, já existiam na região 3 vilas (Taubaté, Jacareí e Guaratinguetá), 2 povoados religiosos (Pindamonhangaba e Tremembé) e 2 aldeamentos indígenas (Nossa Senhora da Escada e São José) (MÜLLER, 1969, p. 19).

9. As Aldeias dos Reis foram introduzidas na Capitania pelo governador-geral Mem de Sá, em 1560.

Cadernos de Arquitetura e Urbanismo, v.22, n.31, $2^{0}$ sem. 2015 
Logo após sair de São Paulo no sentido do Vale do Paraíba, o caminho seguia em direção a Mogi das Cruzes e, desse ponto, a Jacareí até atingir a Vila de Taubaté. A abertura desse vetor de expansão (ao longo do rio Paraíba do Sul), juntamente com a descoberta de ouro de aluvião e a fundação dos primeiros núcleos de povoamento as margens do rio intensificaram a migração a partir da Vila de Piratininga em direção ao sertão do vale. Já no século XVII, a busca do ouro mudou novamente o eixo de ocupação territorial na capitania, desviando-se para a região da atual cidade de Taubaté.

A vila de Taubaté se tornou o mais importante núcleo de povoamento do Vale do Paraíba no século XVII. A maior parte dos bandeirantes nasceu nessa vila (TAUNAY, 1981). Assim como a Vila de Piratininga no século XVI, Taubaté tinha, no século XVII, uma ligação direta entre o sertão e o mar que se abria em duas outras vias: uma em direção ao porto de Ubatuba e outra ao porto de Parati. O caminho entre Taubaté e Ubatuba era uma antiga trilha indígena. Essa via foi de grande importância para o escoamento da produção de ouro, tanto que Taubaté se tornou um ponto do Registro, isto é, uma alfândega da Coroa portuguesa para o controle de mercadorias vindas do sertão. Nesse momento, havia dois fluxos de pessoas e mercadorias importantes confluído em direção a Taubaté: o contingente populacional proveniente da Vila de Piratininga e aquele vindo das minas.

\section{O terceiro ciclo de migração e fixação: expansão do Caminho dos Bandeirantes rumo às minas, no século XVIII}

No século XVIII, com a intensificação do tráfego de tropeiros, viajantes e bandeirantes no sentido das minas, surgiam novos núcleos de povoamento, como Caçapava, Piedade (depois conhecida como Lorena) e Caixoeira Grande, (posteriormente chamada de Cachoeira Paulista).
Figura 2 • Detalhe do Mappa da Capitania de S. Paulo, 1751 a 1755

Fonte: Mappa da capitania de S. Paulo, e seu sertão em que devem os descobertos, que lhe forão tomados para Minas Geraes, como tambem o camiho de Goyazes, com todos os seus pouzos, e passagens. Francisco Tosi Columbina, Coleção Morgado de Matheus, Catalogação n. ${ }^{0}$ cart 1033415, Fonte BN arquivo digital.

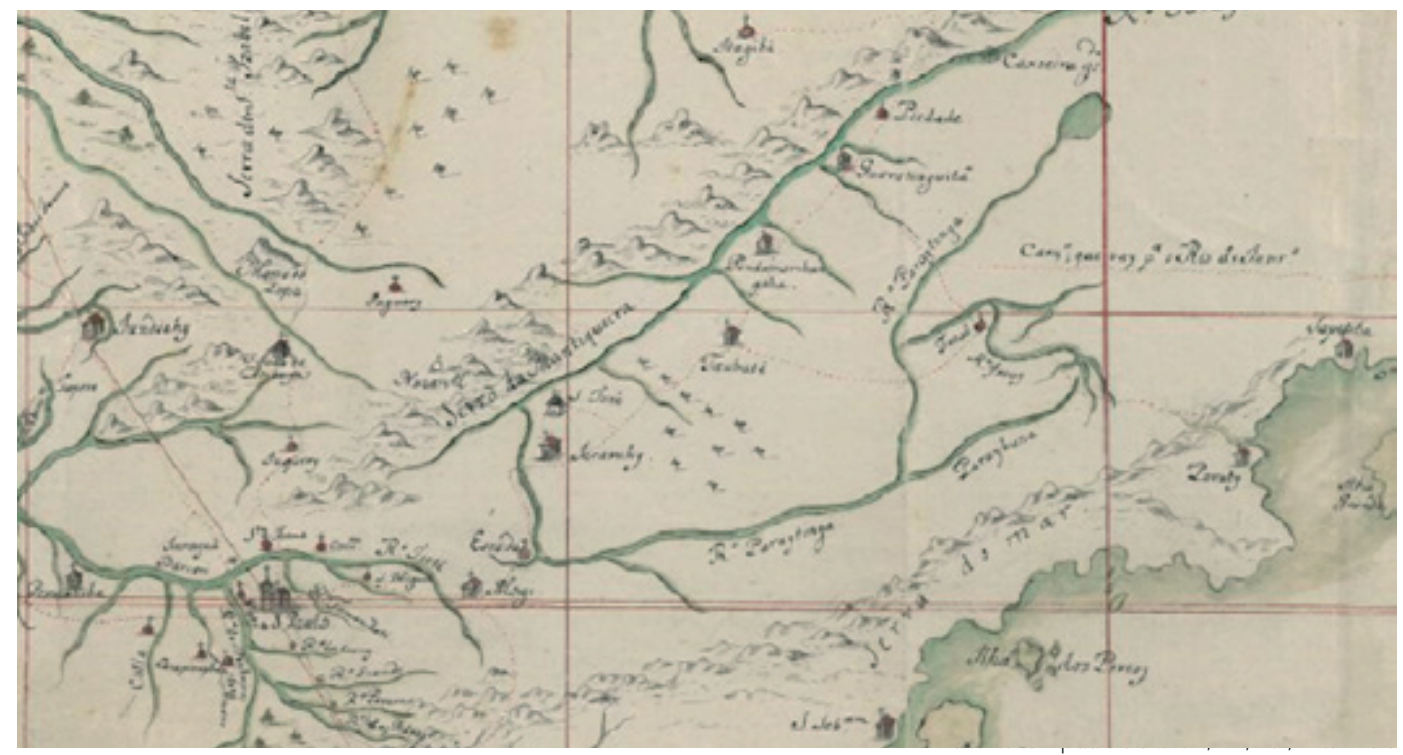


O Caminho dos Bandeirantes margeava o Rio Paraíba até Guaratinguetá e, dessa vila, seguia até Piedade e, por fim, Caixoeira Grande, a última vila da Capitania de São Paulo. O caminho prosseguia atravessando a "Garganta do Embaú na Serra da Mantiqueira", até chegar nas ditas minas (FIG. 2).

No século XVIII, os caminhos abertos pelos colonizadores junto com os indígenas formavam uma malha viária de comunicação entre o sertão e o mar. O Caminho dos Bandeirantes era paralelo ao mar, entre as serras marítimas e da Mantiqueira, enquanto os outros caminhos foram abertos no sentido transversal a esse primeiro, isto é, formavam as vias de comunicação entre o sertão e o mar seguindo no sentido perpendicular a esses dois acidentes geográficos. Um dos caminhos que merecem destaque é o que liga Guaratinguetá até Parati. No século XVIII, ao longo desse caminho, havia três pequenos povoados: Campo Alegre, Facão ${ }^{10}$ e Boa Vista. Mas, por uma decisão das autoridades eclesiásticas, em 1723, Facão foi escolhido para receber a paróquia dessa região e, em 1785, foi elevada a vila e nomeada de Nossa Senhora da Conceição de Cunha (MÜLLER, 1969, p. 22).

Do planalto, ligando-se com a estrada de São Paulo ia até Taubaté e daí as Minas, uma vai alcançar a porção do território, agora chamada "zona do alto Paraíba," região do Rio Paraitinga: seguia até a "borda do campo de Facam" (área de Cunha) onde um ramo dela, no lugar chamado "Encruzilhada," preferia a direção de Ubatuba, enquanto o outro seguia também em direção rumo ao mar, rumo Parati. Este último se converte no principal, posto que era por esse porto que trafegavam os viajantes, o comércio e o ouro que descia das Minas para o Rio de Janeiro (TRINDADE, 1977, p. 9).

Os núcleos de povoamento, vilas e freguesias do Vale do Paraíba foram importantíssimos como apoios aos que trafegavam por esses caminhos. Cada vez mais a vida econômica desses núcleos estava condicionada às vias de comunicação, formando uma rede de núcleos que abasteciam com mantimentos e ofereciam pousos aos tropeiros, viajantes e bandeirantes em seu intento às Minas. O próprio Saint-Hilaire (1822/1974) descreve a urbanização de todo esse caminho. Esses núcleos, vilas e freguesias tinham construções simples que eram uma característica das vilas paulistas. A exceção é justamente a Vila de Taubaté. As casas eram pequenas e próximas umas das outras, verificava-se também que a maioria das fachadas era caiada e com um pequeno quintal (SAINT-HILAIRE, 1822/1974, p. 77).

Tão logo se alcançava a Capitania de Minas Gerais, a primeira cidade do Caminho dos Bandeirantes era Passa Quatro. Essa localidade era a sede, assim como Taubaté, de mais um Registro: o Registro da Mantiqueira. "O Registro da Mantiqueira foi colocado mesmo na raiz da serra e compõem-se da casa da barreira, ocupada pela repartição e dum rancho, no qual fica a balança onde se pesavam as mercadorias vindas do Rio de Janeiro" (SAINT-HILAIRE, 1822/1974, p. 66).

Desse ponto, seguia-se em direção a Pouso Alto, até a Freguesia de Campanha e, desta, a São João del-Rei. Essa cidade foi, no início do século XVIII, o palco da Guerra dos Emboabas.
10. Em alguns outros livros, como veremos posteriormente, alguns autores denominam essa área como Facam. 


\section{A chegada de imigrantes de áreas mais distantes: a formação de novos caminhos e a Guerra dos Emboabas.}

Tão logo os bandeirantes paulistas ocuparam as terras e margens dos rios da Capitania de Minas em busca de riquezas, outros povoadores chegaram ao local. Eram pessoas vindas do Nordeste brasileiro, do Rio de Janeiro e também de Portugal, que traziam um conhecimento tecnológico mais avançado se comparado às técnicas utilizadas pelos bandeirantes para a extração do ouro. Esses imigrantes ficaram conhecidos como emboabas. Ocorreu que os administradores e representantes da Coroa portuguesa no Brasil consideravam os paulistas um povo desqualificado. Os bandeirantes paulistas, reivindicando a posse e a propriedade das terras descobertas, levantaram-se em guerra contra os "invasores". Essa disputa, ocorrida no início do século XVIII, ficou conhecida como Guerra dos Emboabas (TAUNAY, 1981) e teve como cenário as margens do Rio das Mortes e a Vila de São João del-Rei.

Apesar de haver um claro interesse político e econômico da Coroa portuguesa no controle da região aurífera, deve-se destacar a preocupação dos próprios membros da administração portuguesa com respeito ao descobrimento do ouro e o consequente conflito. Os administradores acreditavam que, com a descoberta do ouro e a migração maciça do litoral para região aurífera, havia o risco de desguarnecer militarmente a costa brasileira, com a resultante invasão do território por outros povos, como espanhóis, franceses, etc. Ao mesmo tempo, o conflito entre os bandeirantes e os emboabas também fragilizava as bases políticas e militares da colônia. Havia, portanto, a necessidade de uma rápida solução e posicionamento da Coroa portuguesa a fim de resolver esse entrave. O então Conselho Ultramarino tomou partido em favor dos emboabas, considerando os paulistas os vilões dessa história (SOUZA, 2006, p. 84). Os paulistas perderam essa guerra, e a Coroa portuguesa criou uma série de leis que buscavam restringir o acesso dos paulistas às minas de ouro, entre elas citamos duas: a proibição do antigo Caminho dos Bandeirantes, que ligava Taubaté às minas; e a criação, em 1709, da Capitania Conjunta de São Paulo e Minas do Ouro, em que o porto de Santos ficava sujeito ao Rio de Janeiro. Também algumas medidas políticas da Coroa portuguesa, datadas de 1738 , restringiam as rotas partindo da Vila de São Paulo em direção ao sul e a oeste, nos atuais Estados de Santa Catarina, Rio Grande do Sul e Goiás, demonstrando a intenção de centralização administrativa e, portanto, a intensificação do poder político. Obviamente, outros caminhos clandestinos foram abertos pelos paulistas, na tentativa de alcançar as minas de ouro, mas com muito pouco sucesso. Segundo Trindade (1977), com a publicação da Provisão Régia de 1748, a Coroa Portuguesa fez com que a Capitania de São Paulo perdesse sua autonomia e se tornasse simplesmente uma Comarca do Rio de Janeiro. Consequentemente, a Capitania de São Paulo conheceu um grande período de ostracismo econômico e comercial que se encerrou apenas no fim do século XVIII, com o governo do Morgado de Matheus. ${ }^{11}$
11. No governo de Morgado de Matheus (1765-1775), foram fundados dois povoados no Vale do Paraíba: São Luís do Paraitinga e Santo Antônio (posteriormente conhecido por Paraibuna). As fundações dessas Vilas fizeram parte de uma política de ocupação territorial e militar, com a finalidade de proteção da colônia.

Cadernos de Arquitetura e Urbanismo, v.22, n.31, 2º sem. 2015 
O Movimento Bandeirista surgiu na Capitania de São Paulo alheio às vontades da Coroa portuguesa. Entretanto, após o descobrimento de ouro e pedras preciosas, a Coroa tratou logo de se posicionar como metrópole. O escoamento da produção de ouro se fazia em um trajeto com dois trechos complementares: o primeiro, via terrestre, pelo Caminho dos Bandeirantes, onde o ouro saía de Minas Gerais, seguia pela garganta do Embaú até atingir a Vila de Guaratinguetá e, deste ponto, atravessava a Serra do Facão até o porto de Parati. O segundo trecho era percorrido por via marítima, desse porto até o Rio de Janeiro. Mesmo sendo, naquele momento, a única ligação entre São Paulo e Rio de Janeiro, esse era um caminho perigoso e longo o que dificultava o escoamento da produção de ouro. ${ }^{12}$ Em razão disso, havia a necessidade de uma ligação direta entre as Minas Gerais e o Rio de Janeiro.

A Coroa portuguesa concedeu a Garcia Rodrigues Paes, em 1698, uma sesmaria, além da licença para abertura de estrada que ligasse diretamente o Vale às Minas. Outras sesmarias também foram distribuídas, e essa estrada ficou conhecida como Caminho Novo da Piedade. Afonso de E. Taunay (1981) também relatou, em um trecho de sua obra, as causas que levaram a abertura do Caminho Novo.

Sertão de Cataguazes, nome que os primeiros anos tiveram as chamadas Minas Gerais pela extensão que depois se foram descobrindo e que também pelo tempo adiante se Ihes foi acomodando o nome do sítio de seu descobrimento e como a riqueza Ihes animasse ao comércio e este se fazia com risco do Rio de Janeiro por mar para Parati e desta vila com trabalho de subir a Serra e meter-se nesta estrada, se determinou abrir caminho em direitura das ditas minas, ao Rio de Janeiro como de próximo se tinha executado, o qual se distinguiu com o nome de Caminho Novo deste antigo que ficou sendo o caminho velho (TAUNAY, 1981, p. 99).

Entretanto Píndaro Rodrigues (1980), memorialista nascido em Bananal, apresenta uma outra versão à abertura do Caminho Novo. Na pesquisa de Rodrigues (bem como nos relatos sertanistas de Taunay já apresentados acima), os motivos que levaram a abertura do Caminho Novo da Piedade são similares, porém com versões e personagens distintos. Segundo Píndaro Rodrigues, em 1725, o então governador-geral da Capitania de São Paulo, Rodrigo César Meneses, anunciou ao governo colonial a abertura de um "caminho novo" que, partindo da Freguesia de Hepacaré (região Guaratinguetá), seguia até a Real Fazenda de Santa Cruz, no Rio de Janeiro. Esse caminho atravessava a Serra da Bocaina e seguia em direção à Vila de São João Marcos. Deste ponto, descia a Serra do Mar até atingir a Real Fazenda. Contudo, em 1776, essa estrada foi substituída por outra de menor distância, trazendo vantagens ao tráfego. Com essa descrição e os três mapas datados do século XVIII e XIX, demonstramos os dois caminhos descritos (FIG. 1, 2 e 3).

No mapa "Coleção Morgado de Matheus. Mappa da Capitania de S. Paulo" (FIG. 2), não há uma data precisa, apenas a indicação do século XVIII. Já podemos perceber um caminho
12. Rodrigues (1980), no seu livro "Caminho novo: povoadores de Bananal", transcreveu um trecho do ofício de José Joaquim Machado de Oliveira ao governador do Estado de São Paulo, apontando os riscos da pirataria no litoral brasileiro. 
que seguia da altura do rio Paraitinga e próximo a Guaratinguetá, no sentido do Rio de Janeiro. No próprio mapa, está descrito "Cam que vay pa o Rio de Janro". ${ }^{13}$ No mapa, não há indicação, ao longo dessa via, de núcleos de povoamento, vilas ou freguesias. No "Mapa corographico da Capitania de S. Paulo" (FIG. 3), datado de 1791-1792, o mesmo caminho já aparece denominado "Caminho das Boiadas", praticamente seguindo o mesmo trajeto do anterior que, saindo de Guaratinguetá, chegava à Vila de São João Marcos, já na capitania fluminense. Nesse mapa, ao longo do Caminho das Boiadas, também não há sinais de urbanização, o que nos leva a crer que esse caminho pudesse servir de transporte de mercadorias, porém ainda pouco utilizado. Logo acima do Caminho das Boiadas, vemos descrito "Caminho para o Rio de Janeiro", que parte da Vila de Lorena até a região da Vila de São João Marcos. Este último ficou conhecido como Caminho Novo da Piedade. A sesmaria que foi concedida a Garcia Rodrigues Paes, em 1698, provavelmente deu origem a dois caminhos distintos: um aberto na primeira metade do século XVIII, que ligava a Freguesia de Hepacaré à Real Fazenda de Santa Cruz; e outro caminho, substituindo o primeiro, e mais curto, ligando a Freguesia de Piedade até o Rio de Janeiro, sendo que ambos passavam pela Vila de São João Marcos (SAINT-HILAIRE, 1822/1974). Ao longo desse Caminho Novo da Piedade, alguns povoados foram se formando, os quais posteriormente se tornaram vilas e arraiais, em razão do movimento intenso de tropeiros. Dois desses povoados importantes do Caminho Novo da Piedade eram a Vila de Sant'Ana de Areias, fundada em 1784 e posteriormente conhecida como Areias, e a Vila de Bom Jesus do Livramento, fundada em 1783, que posteriormente ficou conhecida como Bananal. Ambos se formaram em decorrência do patrimônio religioso, ou seja, pela doação, por parte dos fazendeiros, de terras para a construção de capelas.
13. Caminho que vai para o

Rio de Janeiro.
Figura $3 \bullet$ Detalhe do Mappa Corographico da Capitania de S. Paulo mostrando o Caminho das Boiadas

Fonte: Mappa Corographico da Capitania de S. Paulo, 1791 a 1792. Collectanea de Mappas da Cartographia Antiga da Capitania de São Paulo, 1922.

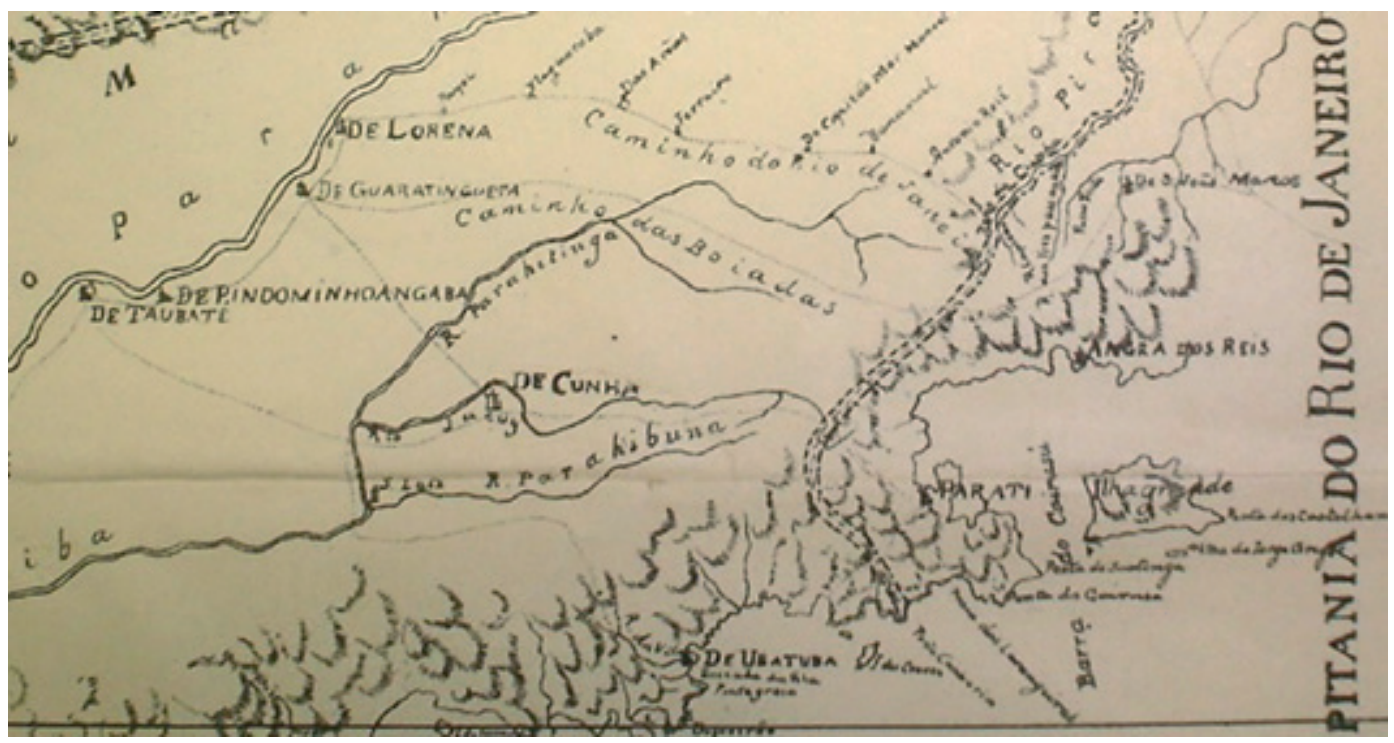


O interessante é perceber que, no primeiro mapa (FIG. 1), datado de 1837, não aparece mais o "Caminho das Boiadas", apenas o "Caminho Novo da Piedade", levando a confirmar a hipótese de não haver tráfego significativo no primeiro, como nos outros caminhos. Outra razão para a ausência de núcleos pode ser constatada por meio da sobreposição de dois detalhes do "Mappa Corographico Capitania de São Paulo de 1837" e o "Mappa Corographico da Capitania de S. Paulo, 1791-1792" (FIG. 1 e 3). Vemos que o trecho percorrido pelo Caminho das Boiadas, além de ter um relevo acidentado, apresenta-se no mapa com a falta de um sistema fluvial que facilite o tráfego, indicando a ausência de fluxos nesse território. O mais importante é compreender as consequências ocorridas com essa abertura de vias. Há uma mudança significativa de eixo econômico do século XVIII, que deu suporte até mesmo para as ações do ciclo cafeeiro no século XIX. Com a abertura do Caminho Novo da Piedade, Minas Gerais agora tinha uma ligação direta com a cidade do Rio de Janeiro, que tornou o Estado fluminense tão importante a ponto de abrigar, na segunda metade do século XVIII, a nova capital do Brasil Colônia.

\section{A cultura do café e a consolidação dos caminhos}

No século XIX, o café já era a principal fonte de renda do Vale do Paraíba. Foi ao longo do "Caminho Novo da Piedade" que os homens mais ricos da região das Minas Gerais estabeleceram suas propriedades após o declínio do ouro. Esse novo vetor de expansão territorial, no século XIX, teve uma grande importância para o escoamento da produção cafeeira.

Nessa época, esses caminhos do Vale do Paraíba já estavam devidamente consolidados e com um intenso tráfego de tropeiros e viajantes. Após o declínio da produção de ouro nas Minas Gerais, os caminhos continuaram a ser utilizados para o escoamento da produção do açúcar e principalmente do café produzido no Vale do Paraíba. Com fim do ciclo do ouro, houve um novo movimento migratório inverso. Com os dados descritos por Rodrigues (1980) sobre as origens das principais famílias da cidade de Bananal, é possível constatar que a população das cidades mineiras e fluminenses retornaram às vilas e freguesias do Vale do Paraíba. Ao retornarem, muitas delas se estabeleceram nas propriedades ao longo Caminho Novo da Piedade ou no antigo Caminho dos Bandeirantes. De fato, a primeira via recebeu um maior número de pessoas e, consequentemente, que possuíam maior poder aquisitivo. Foi o dinheiro proveniente do ciclo do ouro que financiou as novas ações na agricultura, primeiramente na cana-de-açúcar e, depois, no cultivo do café. No primeiro detalhe do "Mappa Corographico da Capitania de São Paulo" (FIG. 2), já é possível perceber o grande número de vias de comunicação na região do Vale do Paraíba, sendo que Bananal ${ }^{13}$ também se tornou um ponto de ligação para o litoral fluminense. Novos núcleos de povoamento surgiram margeando o Caminho Novo da Piedade, como Queluz (1800), Silveiras (1830) e São José do Barreiro (1803) (MÜLLER, 1969, p. 39). Algumas ramificações
13. Bananal se tornou uma das cidades do Vale do Paraíba mais importantes no ciclo cafeeiro. Essa cidade foi motivo de disputas políticas entre São Paulo e Rio de Janeiro, como mostram documentos da Assembleia Legislativa Paulista. Foram os barões do café de Bananal que avalizaram os empréstimos feitos pelo Brasil na Inglaterra, para financiar a Guerra do Paraguai.

Cadernos de Arquitetura e Urbanismo, v.22, n.31, 2º sem. 2015 
foram constituídas a partir do Caminho Novo da Piedade, ligando principalmente o Vale do Paraíba paulista e fluminense além do litoral fluminense.

\section{Considerações finais}

O importante é salientar a relação existente entre os deslocamentos populacionais e a abertura de novas vias em razão das mudanças dos centros econômicos. A primeira ocupação do território paulista ocorreu no litoral, no século XVI. Como vimos, em busca de terras mais propícias à agricultura, ainda no primeiro século, os colonizadores que saíam do litoral, galgavam a Serra do Mar e encontravam, no planalto, melhores condições de sobrevivência. Havia, portanto, uma migração do litoral ao planalto. Posteriormente, os bandeirantes paulistas adentraram os sertões, a fim de escravizar índios e buscar novas terras. Quando no século XVIII encontraram ouro e pedras preciosas nas margens dos rios e principalmente no Sertão de Cataguases (atual Estado das Minas Gerais), houve um novo movimento migratório. O ouro atraía pessoas de todo o País para a região das minas. Com a Guerra dos Emboabas, no século XVII, e as proibições, por parte da Coroa portuguesa, da circulação dos bandeirantes nas vias abertas por eles, a Capitania paulista entrou em um período de ostracismo. Entretanto, para escoar a produção, fez-se necessária a abertura de um novo caminho, que ligava as minas diretamente com o Rio de Janeiro. Este ficou conhecido como Caminho Novo da Piedade. Com essa mudança de eixo econômico, houve nova migração, que se intensificou no declínio do ciclo do ouro e na valorização da economia cafeeira, no século XIX. Ao longo de todas essas vias, foram fundados núcleos de povoamento, vilas e freguesias que serviam de apoio aos que por elas trafegavam, decorrentes da intensificação do comércio ao longo dessas vias.

Temos, assim, uma malha de vias e uma rede de cidades que são verdadeiros palimpsestos dos diferentes momentos de ocupações dos colonizadores nessa área do território. Entendemos que a ocupação do Vale do Paraíba ocorreu em três momentos distintos. O primeiro, caracterizado pela expansão territorial, a partir da Vila de Piratininga, sem grandes pretensões da Coroa portuguesa com a ocupação territorial ou qualquer retorno econômico. O segundo momento se refere ao descobrimento das regiões auríferas e a atenção da Coroa Portuguesa com a proteção e a administração desse território. Por fim, o terceiro momento é caracterizado pelo ciclo cafeeiro, o qual colocou os núcleos urbanos do Vale do Paraíba em evidência sob o ponto de vista econômico.

\section{Referências}

COLLECTANEA de Mappas da Cartographia Antiga da Capitania de São Paulo, 1922. São Paulo: Acervo Biblioteca FAU USP: Obras Raras.

COSTA, Angyone. Introdução à Arqueologia Brasileira: etnografia e história. São Paulo: Companhia Editora Nacional, 1959. 
(Col. Brasiliana, 34.)

HOLANDA, Sérgio Buarque. Raízes do Brasil. 26. ed. São Paulo: Companhia das Letras, 2006.

MONTEIRO, John M. Dos Campos de Piratininga ao Morro da Saudade: a presença indígena na história de São Paulo. In: PORTA, Paula (org.). História da cidade de São Paulo: a cidade colonial. v. 1. São Paulo: Paz e Terra, 2004.

MÜLLER, Nice Lecocq. 0 fato urbano na bacia do Rio Paraíba. Rio de Janeiro:

IBGE Divisão Cultural, 1969.

OMEGNA, Nelson. A cidade colonial. Brasília: Ebrasa, 1971.

PRADO JUNIOR, Caio. A cidade de São Paulo: geografia e história. São Paulo: Brasiliense, 1989.

RIBEIRO, Darcy. O povo brasileiro: a formação e o sentido do Brasil. São Paulo: Companhia das Letras, 1995.

RODRIGUES, Pindaro de Carvalho. Caminho novo: povoadores do Bananal.

São Paulo: Governo do Estado de São Paulo, 1980.

SAINT-HILAIRE, Auguste de. Segunda viagem do Rio de Janeiro a Minas Gerais e a São Paulo (1822). Tradução revista e prefácio de Vivaldi Moreira. Belo Horizonte: Itatiaia; São Paulo: Edusp, 1974.

SOUZA, Laura de Mello e. O sol e a sombra: política e administração na

América portuguesa do século XVIII. São Paulo: Editora Companhia das Letras, 2006.

TAUNAY, Afonso de E. Relatos sertanistas. Belo Horizonte: Itatiaia; São Paulo: Edusp, 1981.

TELLES, Augusto C. da Silva. O vale do Paraíba e a arquitetura do café. Rio de Janeiro: Capivara, 2006.

TRINDADE, Jaelson Bitran. No caminho do Paraitinga in São Paulo do Paraitinga. v. 2. São Paulo: Conselho da Defesa do Patrimônio Histórico, Arqueológico, Artístico e Turístico do Estado de São Paulo; Secretaria da Cultura, Ciência e Tecnologia do Governo do Estado de São Paulo, 1977.

Recebido em: 20/07/2015

Aprovado em: 29/02/2016 